\title{
OP61
}

\section{WHAT TYPES OF VISUAL ENVIRONMENT CAN REDUCE THE PERCEPTION OF NOISE IN URBAN RESIDENTIAL DISTRICT?}

\author{
Jialu WU et al.
}

DOI 10.25039/x46.2019.OP61

from

CIE x046:2019

Proceedings

of the

29th CIE SESSION

Washington D.C., USA, June 14 - 22, 2019

(DOI 10.25039/x46.2019)

The paper has been presented at the 29th CIE Session, Washington D.C., USA, June 14-22, 2019. It has not been peer-reviewed by CIE.

(C) CIE 2019

All rights reserved. Unless otherwise specified, no part of this publication may be reproduced or utilized in any form or by any means, electronic or mechanical, including photocopying and microfilm, without permission in writing from CIE Central Bureau at the address below. Any mention of organizations or products does not imply endorsement by the CIE.

This paper is made available open access for individual use. However, in all other cases all rights are reserved unless explicit permission is sought from and given by the $\mathrm{CIE}$.

CIE Central Bureau

Babenbergerstrasse 9

A-1010 Vienna

Austria

Tel.: +43 17143187

e-mail: ciecb@cie.co.at

www.cie.co.at 


\title{
WHAT TYPES OF VISUAL ENVIRONMENT CAN REDUCE THE PERCEPTION OF NOISE IN URBAN RESIDENTIAL DISTRICT?
}

\author{
Jialu Wu, Biao Yang \\ School of Architecture, Harbin Institute of Technology, Shenzhen, Guangdong, CHINA \\ yangbiao@hit.edu.cn
}

DOI 10.25039/x46.2019.OP61

\begin{abstract}
The effect of non-acoustical factors including the type of visual environment on human noise perception has been found. Therefore, the perception of noise in the urban residential can be mitigated by the design of landscapes in the urban environment. This paper investigated the influence of visual environment on perceived loudness of urban noise to people. The experiment was under the virtual reality(VR) technique. A total of 80 audio-visual stimuli with $40360^{\circ}$ panoramic photos and two loudness ranges traffic noise (a low decibel range $50 \mathrm{~dB}$ to $60 \mathrm{~dB}$ and a high decibel range $60 \mathrm{~dB}$ to $70 \mathrm{~dB}$ ) were presented by a virtual reality helmet and a headset. The 30 participants were asked to evaluate the visual environments and then listen to the audio stimuli. An loudness matching task was perform immediately afterwards by pressing increase or decrease button embedded in a neutral background without any visual scene. The difference of perceived loudness and actual loudness (overestimation or underestimation in $\mathrm{dB}$ ) was recorded as dependent variable, whilst greening rate, degree of spatial openness, waterscape rate, artificial landscape rate, hue, colour saturation and lightness were calculated to be used as independent variable. The statistical results show that loudness difference is correlated with colour saturation $(p=0.035)$ and greening rate $(p=0.007)$ in the visual environments. People assessed to higher greening rate and colour saturation may be more sensitive to noise. In addition, initial results of linear fitting indicate that $17 \%$ increase of green rate might be linked with $1 \mathrm{~dB}$ overestimation of sound pressure level $(\mathrm{SPL})$.
\end{abstract}

Keywords: Visual environment, Perceived loudness, Virtual reality

\section{Introduction}

In the design of urban environment, noise control is a very important consideration for it prevents the interference on people's daily life and potential hazard on people's health. Vision is the central sense of human beings, about $87 \%$ of external information is obtained through vision. Some studies indicate that people's perception of sound is affected by visual environment factors to a great extent, such as botanical landscape, water landscape, colour of landscape and so on.

Several researchers have studied the objective and participantive characteristics of composition of landscape elements, such as noise barriers, wind turbine, natural landscape, urban spatial form and so on. Hong and Geno (2014) remarked about the perceived noise reduction combined with visual impressions of five different barrier types: aluminum, timber, translucent acrylic, concrete, and vegetated barriers. Noise annoyance, preconceptions regarding the noise attenuation performance of the barrier, the esthetic preference, and the overall preference for noise barriers were assessed through laboratory experiments. The results of the experiments revealed that barriers covered with vegetation increased the perceived noise barrier performance with increasing esthetic preference and preconceptions of noise reduction. However, a similar research conducted by Kang et al.(2016) has concluded a different conclusion. They investigated the performance of noise barriers in mitigating environmental impact of motorways, taking into consideration their effects on reducing visual intrusions of moving traffic, but also potentially inducing visual impact themselves. A laboratory experiment with computer-visualised video scenes and motorway traffic noise recordings is carried out and the results showed that the transparent barrier did not perform much differently from the timber barriers but tended to be the least effective in 
most scenarios. Li et al.(2010)(2012) and Tang et al.(2017) conducted a series of research in order to reveal the relationships between long-term noise annoyance and different types of neighborhood views, There are totally 2033 questionnaire responses were collected for studying the effect of perceptions of different combinations of views of sea, urban, river, greenery, and/or noise barrier on the annoyance responses from residents living in high-rise apartments in Hong Kong. Results showed that views of sea, urban river, or greenery could lower the probability, while views of noise barrier could increase the probability. Pedersen and Larsman (2008) were explored the visibility of the noise source, visual attitude and vertical visual angle in different landscapes. Data from two typical field studies carried out among people living near wind turbines were recorded. The results indicated that attitude towards a noise source, well known to influence the response to noise, comprises a visual constituent in some situations.

The relationship between noise perception and colour were also studied. Menzel and Fastl (2007) and Hui (2011) both investigated the effect of images of differently coloured objects on the loudness of a simultaneously perceived traffic noise. Both of their results indicated that red can enhance the perceived loudness and annoyance of traffic noise. Maffei et al. (2013) Investigated the influence of the number and the colour of wind turbines on global, visual and auditory judgment by using the Immersive Virtual Reality technique in a laboratory experiment. The results showed that the visual component has a weak effect on individual reactions.

The control of urban noise should consider the influence of visual environment factors. The past studies have found some visual factors in urban environments that have influence on noise perception, but the degree of influence have not been measured quantitatively. The aims of this study were to find out the visual environment factors influenced on the perception of noise, to ascertain the direction (more tolerance or less) of its influence and to measure the degree of its influence. The results are expected to be used in guidance and standard of visual environment design.

\section{Method}

\subsection{Audio-visual stimuli}

In this study, visual scenes and auditory stimuli were created in laboratory. Visual scenes were downloaded from an free panorama material website (texturify.com). These photos were selected with two criteria: basing on human perspective and including as much landscapes as possible that are accessible to human. In addition to residential landscapes, these photos also include many natural landscapes. The numerous kinds of landscapes of photos allow significant differences among those visual stimuli. Figure 1 shows some typical panorama photos used in this study. Then, a total of $40360^{\circ}$ panoramic photos as the visual stimuli were taken by KanDao $\AA$ obsidian go $3 \mathrm{D}$ virtual reality camera and played by $\mathrm{HTC} \circledast$ vive pro virtual reality helmet. 

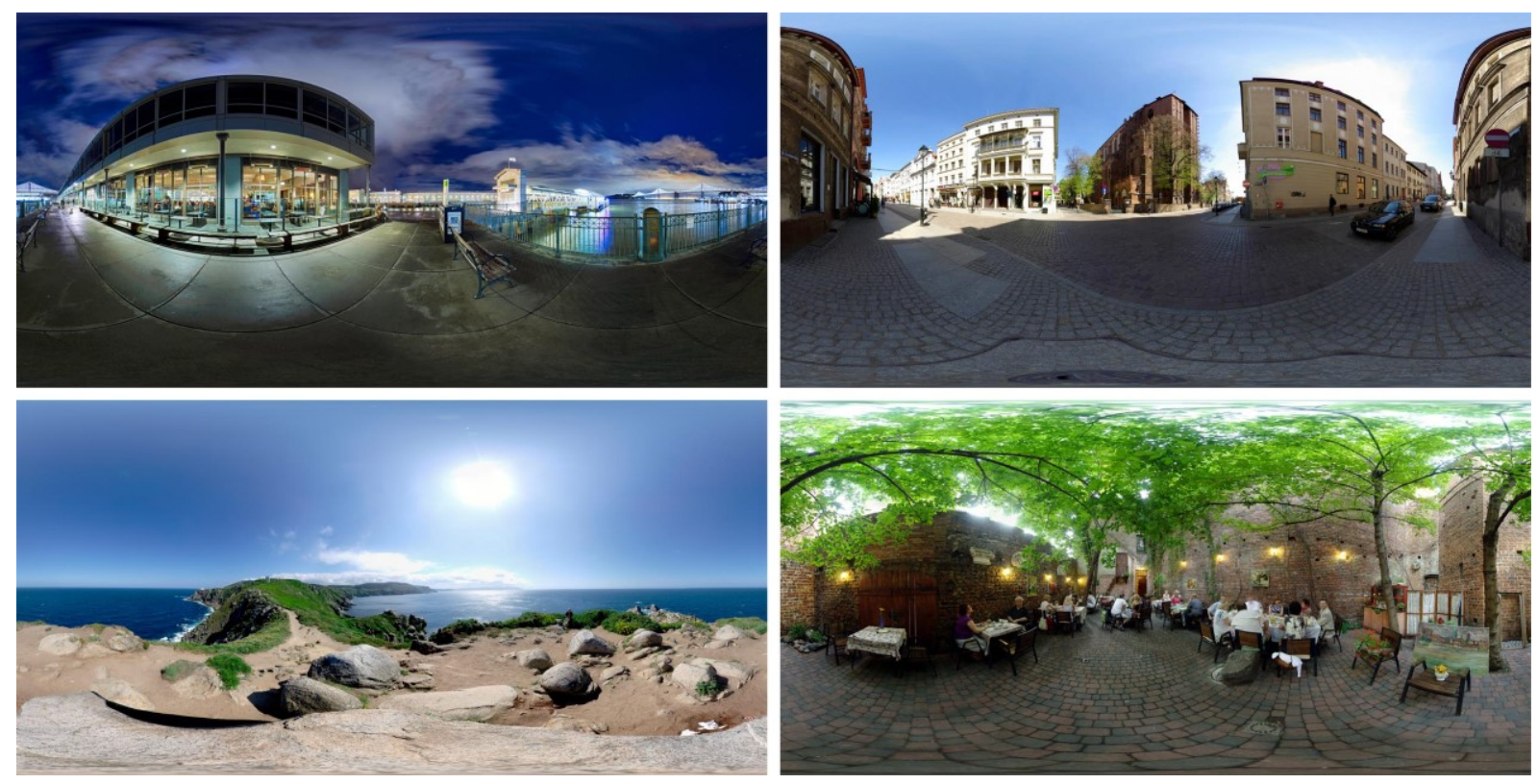

Figure 1 - Four typical $360^{\circ}$ panorama photos

The auditory stimuli were typical urban traffic noises, vary in 2 ranges of sound pressure level (SPL) which include a low decibel range $(50 \mathrm{~dB}$ to $60 \mathrm{~dB})$ and a high decibel range $(60 \mathrm{~dB}$ to $70 \mathrm{~dB}$ ) corresponding to the range of noise exposure in most urban spaces. The auditory stimuli were present through Sennheiser® HD800S headphone. In total, 80 audio-visual combinations ( 40 visual stimuli $X 2$ ranges of audio stimuli) were created.

\subsection{Participants}

The 80 audio-visual combinations were randomly presented to 21 participants ( 9 females and 12 males; Age range $=18-29$ years) without visual or auditory diseases. These were recruited from undergraduate and graduate students at universities and young people working in the surrounding area.

\subsection{Experimental design}

An experimental program produced by unity ${ }^{\circledR}$ was applied in this experiment. For each visual stimulation, there were two audio stimulation that play randomly from each of the 2 sound ranges. The order of presentation of the 40 photos stimuli was also randomized. In the laboratory experiment, a photo is showed and then the participants were asked to rate their preferences for the visual environment using an 5-point scale $(-2,-1,0,1,2)$ by a click of the handle. 4 pairs of bipolar adjectives were selected and show in the virtual reality helmet: artificial-natural, high greening rate-low greening rate, warm colour-cool colour, colourfulmonochromatic, with -2 representing the extreme degree of "artificial, high greening rate, warm colour and colourful" and 2 representing the extreme degree of "natural, low greening rate, cool colour and monochromatic". The purpose of visual rating was to help the participants immerse themselves into the virtual environment. The audio stimuli was played with the duration of $7 \mathrm{sec}$ after the visual rating. An loudness matching task was perform immediately afterwards by pressing increase or decrease button embedded in a neutral background without any visual scene. The SPL of both stimulating sound and adjusting sound were automatically recorded by unity ${ }^{\circledR}$. During the experiment process, the participants had a chance to rest after 40 rounds of experiments.

\section{Results}

Data was extracted from a total number of 1680 responses. All panorama images were unfolded into six plane images (Cubemap), which were equivalent to the six directions. Figure 2 shows two examples of Cubemaps. 

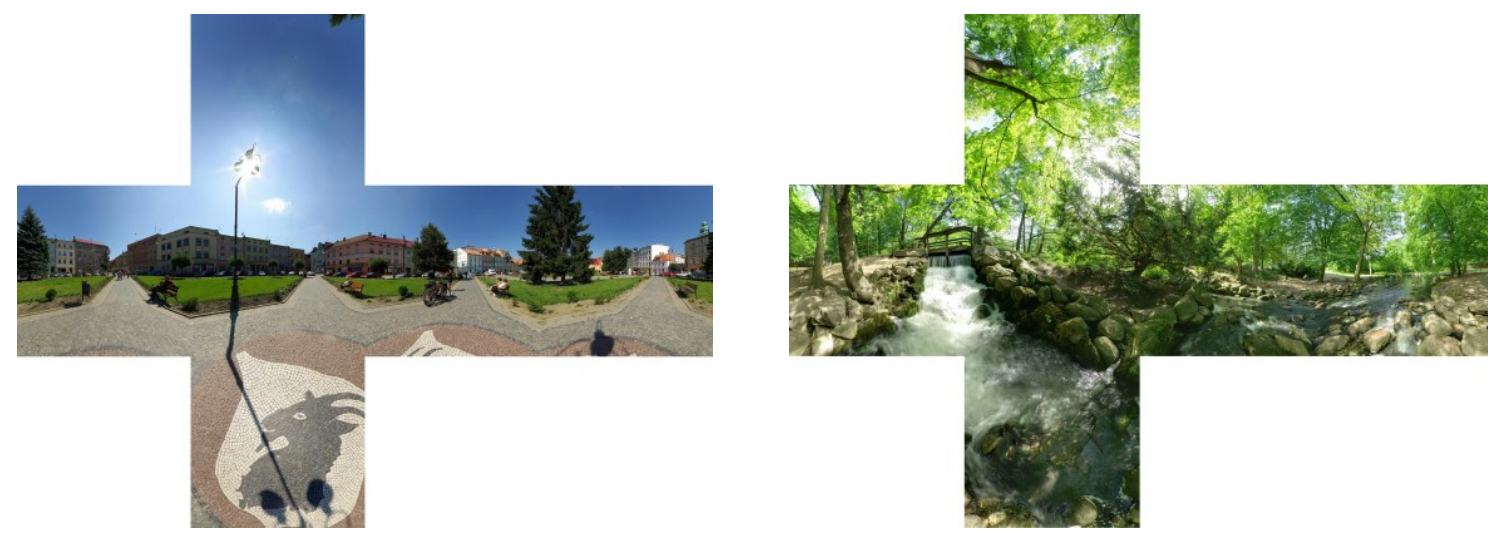

Figure 2 - two examples of Cubemaps

Analyses of visual environment factors were performed on the Cubemap. Two main categories of visual factors were considered in this experiment: composition of landscape elements, colour information. HSL (Hue, Saturation and Lightness) was used as colour factor of visual environment. Average hue, saturation and lightness of each image were calculated by MATLAB®. Composition of landscape elements involved greening rate, degree of spatial openness, waterscape rate and artificial landscape rate. These were measured by the percentage of area of the specific composition in the whole image. The degree of spatial openness is represented by sky rate. The difference of loudness ( $L d B>0$ : overestimation; $\mathrm{LdB}<0$ : underestimation) was recorded as dependent variable.

The results show in table 1 and table 2 indicate that loudness difference significantly correlated to saturation and greening rate. Significant relationships were found between loudness difference and greening rate $(p=0.007)$; loudness difference and saturation $(p=0.035)$. No significant relationships were observed between loudness difference and hue, lightness, degree of spatial openness, waterscape rate or artificial landscape rate. In addition, initial results of linear fitting indicate that $17 \%$ increase of green rate might be linked with 1 $\mathrm{dB}$ overestimation of SPL.

Table 1 - Correlations of loudness difference and composition of landscape elements Correlations

difference green openness waterscape artificial

\begin{tabular}{lllllll}
\hline difference & $\begin{array}{l}\text { Pearson } \\
\text { Correlation }\end{array}$ & 1 & $.421^{* *}$ & -.204 & -.213 & -.126 \\
\cline { 2 - 7 } & Sig. (2-tailed) & & .007 & .207 & .186 & .437 \\
\hline $\mathrm{N}$ & 40 & 40 & 40 & 40 & 40
\end{tabular}

**. Correlation is significant at the 0.01 level (2-tailed).

Table 2 - Correlations of loudness difference and colour information

\begin{tabular}{|c|c|c|c|c|c|}
\hline & & $\begin{array}{l}\text { Correlatio } \\
\text { difference }\end{array}$ & $\begin{array}{l}\text { is } \\
\text { hue }\end{array}$ & saturability & lightness \\
\hline \multirow[t]{3}{*}{ difference } & $\begin{array}{l}\text { Pearson } \\
\text { Correlation }\end{array}$ & 1 & -.088 & $.334^{*}$ & -.221 \\
\hline & Sig. (2-tailed) & & .590 & .035 & .170 \\
\hline & $\mathrm{N}$ & 40 & 40 & 40 & 40 \\
\hline
\end{tabular}




\section{Conclusion}

In this study, the relationship between visual environment factors and the perception of noise was investigated. It was found that two visual environment factors have relationship with perceived loudness of noise: saturation and greening rate. In addition, loudness difference is positively correlated with saturation and greening rate.

It should be noted that the conclusion about greening rate is different from a group of previous studies that green plants can reduce people' annoyance of noise. This may be result from the different dependent variable in this study. In other word, perceived loudness may present a different trend of variation from noise annoyance in some conditions. In addition, in an environment with a high rate of greening, the appearance of noise may seem abrupt since people did not expect the appearance of noise in advance. On this occasion, people may overestimate the loudness of noise. For further study, more precise ways of participant assessment on perceived loudness and categories of visual environment factors need to be explored.

\section{References}

HONG J Y, Jeon J Y . 2014. The effects of audio-visual factors on perceptions of environmental noise barrier performance. Landscape and Urban Planning,125:28-37.

JIANG L , Kang J . 2016. Combined acoustical and visual performance of noise barriers in mitigating the environmental impact of motorways. Science of the Total Environment, 543(Pt A):52-60.

Li H N , Chau C K, Tang S K . 2010. Can surrounding greenery reduce noise annoyance at home?. Science of the Total Environment, 408(20):4376-4384.

Li H N , Chau C K, Tse M S, et al. 2012, On the study of the effects of sea views, greenery views and personal characteristics on noise annoyance perception at homes. The Journal of the Acoustical Society of America, 131(3):2131.

MENZEL, D. Fastl H. 2008. Influence of vehicle colour on loudness judgments. The Journal of the Acoustical Society of America, 123, 2477-2479.

MA H, Song J W, Yang Q et al.2011. Study on the influence of colour perception on participantive evaluation of road traffic noise annoyance. Southern Architecture, 77-79 (in Chinese)

MAFFEI L, lachini T, Masullo M, et al. 2013. The effects of vision-related aspects on noise perception of wind turbines in quiet areas. International Journal of Environmental Research \& Public Health, 10(5):1681-1697.

PEDERSEN E, Larsman P . 2008. The impact of visual factors on noise annoyance among people living in the vicinity of wind turbines. Journal of Environmental Psychology, 28(4):379-389.

TANG S K, Leung T M, Xu J M, et al. 2017. The effects of neighborhood views containing multiple environmental features on road traffic noise perception at dwellings. Journal of the Acoustical Society of America, 141(4):2399-2407. 